University of Montana

ScholarWorks at University of Montana

7-26-2003

\title{
High altitude Himalayan climate inferred from glacial ice flux
}

Joel T. Harper

University of Montana - Missoula, joel.harper@mso.umt.edu

Neil Humphrey

University of Wyoming

Follow this and additional works at: https://scholarworks.umt.edu/geosci_pubs

Part of the Geology Commons, Glaciology Commons, and the Hydrology Commons Let us know how access to this document benefits you.

\section{Recommended Citation}

Harper, J. T., and N. F. Humphrey, High altitude Himalayan climate inferred from glacial ice flux, Geophys. Res. Lett., 30(14), 1764, doi:10.1029/2003GL017329, 2003.

This Article is brought to you for free and open access by the Geosciences at ScholarWorks at University of Montana. It has been accepted for inclusion in Geosciences Faculty Publications by an authorized administrator of ScholarWorks at University of Montana. For more information, please contact scholarworks@mso.umt.edu. 


\title{
High altitude Himalayan climate inferred from glacial ice flux
}

\author{
Joel T. Harper and Neil F. Humphrey \\ Department of Geology and Geophysics, University of Wyoming, Laramie, WY, USA \\ Received 13 March 2003; revised 17 April 2003; accepted 29 April 2003; published 26 July 2003.
}

[1] Glaciological processes are modeled to investigate precipitation patterns and the resulting mass flux of snow and ice across Himalayan topography. Our model tracks the accumulation and ablation of snow and ice and the transport of snow and ice across the topography by glacier motion. We investigate high elevation precipitation on the Annapurna Massif by comparing the existing ice cover with model-simulated glaciers produced by a suite of different precipitation scenarios. Our results suggest that precipitation reaches a maximum level well below the elevation of the highest peaks. Further, essentially no snow accumulates on the topography above an elevation of $6200-6300 \mathrm{~m}$. Hence, the upper $1000+\mathrm{m}$ of the massif is a high elevation desert with little flux of snow and ice. Active glaciers are limited to a band of intermediate elevations where a maximum of about $60 \%$ of the landscape is covered by moving ice. INDEX TERMS: 1863 Hydrology: Snow and ice (1827); 3354 Meteorology and Atmospheric Dynamics: Precipitation (1854); 1854 Hydrology: Precipitation (3354); 1625 Global Change: Geomorphology and weathering (1824, 1886). Citation: Harper, J. T., and N. F. Humphrey, High altitude Himalayan climate inferred from glacial ice flux, Geophys. Res. Lett., 30(14), 1764, doi:10.1029/2003GL017329, 2003.

\section{Introduction}

[2] The climate of high altitude mountain regions is poorly known due to the logistical difficulties of maintaining observation networks in remote areas, problems associated with measuring precipitation at windy, snowfall-dominated sites, and the large spatial variability caused by rugged terrain. Climate processes of mountain regions are an important component of regional scale earth systems, such as the forcing between ocean circulation and continental precipitation [e.g., Shrestha, 2000] and the coupling between erosion and tectonic uplift [e.g., Beaumont et al., 1992; Willett, 1999]. Perhaps no where else are high elevation climate processes more relevant than central Asia's Himalaya Range. Due to extreme elevations and high erosion rates, the Himalaya is a preeminent locality for testing hypotheses related to the influence of erosion on the partitioning of deformation within orogenic belts [Burbank et al., 1996].

[3] Orographic precipitation processes are commonly assumed to be in operation along the southern Himalayan front. Precipitation with orographic enhancement has been documented along Himalayan peaks and ridges [Higuchi et al., 1982] and as high as $4400 \mathrm{~m}$ elevation [Barros et al., 2000]. Numerical experiments imply that orographically enhanced precipitation reaches a maximum at a lower elevation (upwind) than a topographic divide [Carruthers and Choularton, 1986; Choularton and Perry, 1986]. Supporting observations in the Himalaya are limited, although Bagchi [1982] concludes that precipitation must begin to decrease at some elevation based on analysis of stream flows. Kuhle [1986] noted that intermediate elevations have greater snow and ice cover than high elevations; the flanks of most high Himalayan peaks, including Mt. Everest and Annapurna II, lack significant ice or snow flutes, for example. Thus, theory and indirect evidence suggest that precipitation diminishes at high elevation, but the degree and the elevation of this decrease remain unclear.

[4] Here we investigate vertical gradients in climate and the mass-flux of snow and ice within the Himalaya's Annapurna Massif. We approach the problem from the perspective of glaciological processes, making use of the fact that glaciers integrate climate conditions over time and over large areas of complex topography. Modeling and observations are used to construct first-order descriptions of glaciers and the climate that generates them, which we then use to investigate precipitation high above the reach of observational networks.

[5] The Annapurna Range in central Nepal (Figure 1) is a broad massif that extends roughly $50 \mathrm{~km}$ east-west and $25 \mathrm{~km}$ north-south, and has nine summits above $7000 \mathrm{~m}$. Our study focuses on Lamjun Himal, the south-east quadrant of the massif. This region has ten unnamed glaciers refered to herein as numbers $1-10$ (Figure 1). Six of the glaciers have accumulation basins that extend to elevations well over $5500 \mathrm{~m}$. Terminus elevations of the study glaciers are highly variable, ranging from $2550 \mathrm{~m}$ to $4800 \mathrm{~m}$. These south-facing glaciers are influenced by the same general storm track and have similar rain-shadow and shading effects. Topography of the Annapurna Massif is dominated by steep, high relief slopes; forty degree slopes extending more than $1000 \mathrm{~m}$ vertically are common.

\section{Methods}

[6] We model snow and ice flux across the landscape using a cellular automata technique. Our model is purposefully simple because our focus is on a first-order representation of climate and glaciers at the scale of the mountain range. Our approach is to strike a compromise between mass-balance models appropriate for large scales but with no representation of glacier dynamics [i.e., Hostetler and Clark, 2000] and complex models of glacier dynamics practical only for individual glaciers or reaches of glaciers [i.e., Blatter, 1995]. Input to our model consists of landscape topography and an elevation-dependent mass-balance curve. The model tracks the accumulation and ablation of snow and ice, and its redistribution by glacier motion. The model is run until the glaciers are in steady state with the 


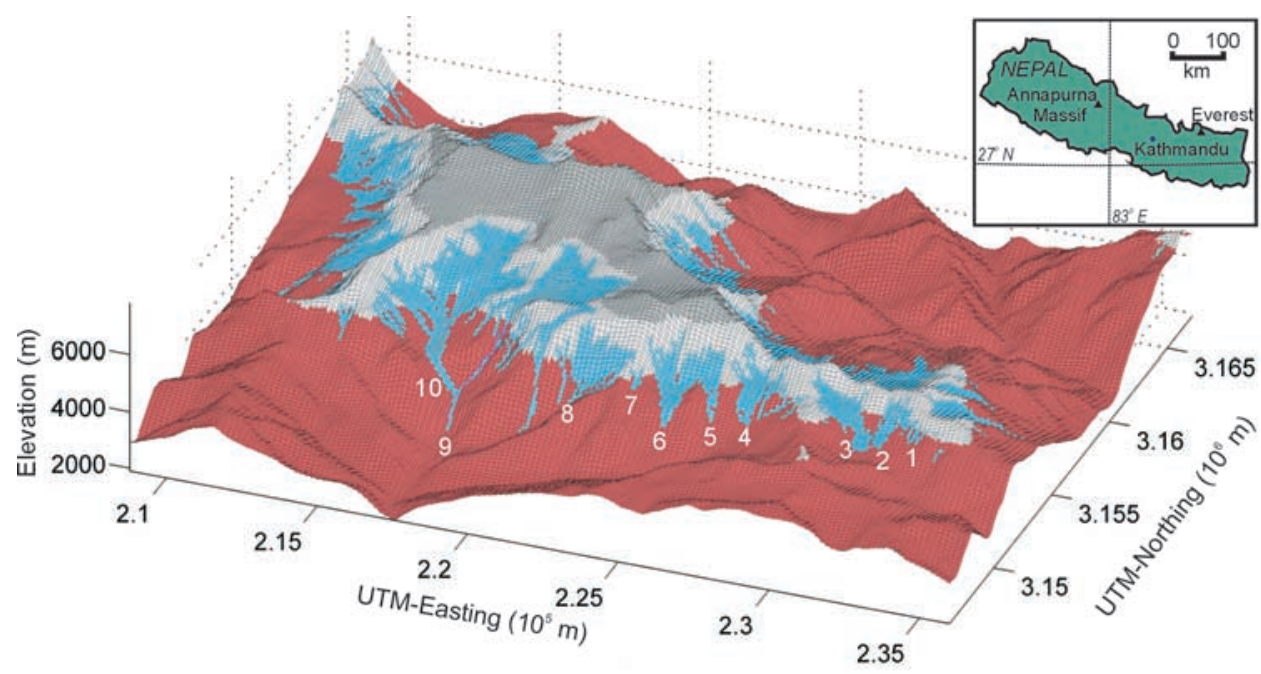

Figure 1. Topography and snow and ice flux for a model run with diminishing snowfall at $6200 \mathrm{~m}$. Study glaciers identified by number. Blue = positive ice flux; white $=$ above ELA with no significant ice flux; gray $=$ zone of diminished snowfall; brown $=$ no snow or ice. Positive ice flux defined as values greater than that produced by a $5 \mathrm{~m}$ thick snowpack moving at $\mathrm{m}$ per year. Inset shows location of Annapurna Massif, central Nepal.

prescribed climate. We use the model to explore scenarios of reduced precipitation at high elevation. We term the elevation where snowfall diminishes the "DSE" (Diminished Snowfall Elevation). We compare real-world glacier geometries to those produced by the model under different DSE scenarios. Hence, we use the model to find the high elevation precipitation pattern that yields a geometry and ice flux consistent with existing glaciers.

\subsection{Model Construct}

[7] The landscape is discretized into a regular hexagonal lattice computed from a 100-m resolution digital elevation model. Particles representing the water equivalent of snow and ice are added to and removed from the lattice following rules of precipitation and ablation. Time steps are made to depict mean annual climate conditions. Particles move within the lattice synchronously, at discrete time steps. The ice is considered plastic with a yield stress of 1 bar (105 Pa) [Nye, 1951] and so glacier motion, including deformation and sliding, accommodates flux to maintain the basal shear stress at the yield stress. The flux determines the velocity and geometry of glaciers. Plasticity is a widely applied simplification in glacier flow modeling [Paterson, 1994 , p. 240], and holds to the first order provided that along-glacier shear is the dominant mode of deformation. A large body of observational and analytical evidence supports this assumption [Paterson, 1994; Bahr and others, 1997], including in situ measurements of the full strain rate tensor in a valley glacier [Harper et al., 2001].

\subsection{Mass-Balance Parameters}

[8] Dyurgerov [2002] analyzed worldwide mass-balance records and showed the mass-balance versus elevation curve is remarkably similar for all glaciers when averaged over multiple years, and normalized with respect to magnitude and elevation range. Our mass-balance versus elevation curve follows this common pattern (Figure 2) with calibration to the appropriate magnitude and elevation distribution of the study region. Three elements of the curve were calibrated: 1) the ELA, 2) the balance gradient, 3) the magnitude of maximum accumulation.

[9] In our determination of the climatic ELA, we disregarded glaciers with steep and large-area headwalls which might cause the glacier's ELA to be dictated by local avalanche processes. Field observations, elevation data, aerial photographs and satellite imagery were used to identify two glaciers (Glaciers 1 and 2) with no avalanche accumulation. The transient snowlines of these glaciers at the conclusion of the Fall ablation season suggest the ELA is approximately $5050 \mathrm{~m}$.

[10] We calibrated the balance gradient and maximum accumulation by finding values that produce low-elevation model glaciers with the same geometry and terminus elevations as their real-world counterparts. We calibrated the model to four low elevation glaciers (Glaciers 1-4) that do not extend above $5500 \mathrm{~m}$ and are therefore assumed to be below the diminished snowfall elevation. Data from Glacier AX010, the only Nepalese glacier with extended term mass-balance measurements [Ageta and Kadota, 1992; Fujita et al., 2001], were used as a starting point for finding calibration values. Glacier AX010's balance gradient is about $10 \mathrm{~mm} / \mathrm{m}$ and it's maximum accumulation is about $0.75 \mathrm{~m}$ of water equivalent. Through repeated model runs we found a good calibration with a mass-balance gradient of $8 \mathrm{~mm} / \mathrm{m}$ and a maximum mass-balance of $1 \mathrm{~m} / \mathrm{yr}$.

[11] We cannot rule out the possibility that a calibration satisfying our criteria may exist for a different suite of values for the ELA, balance gradient, and maximum accumulation. However, several lines of evidence suggest that none of our chosen values could be significantly different. First, field evidence suggests that the ELA is within a few 10 s of meters of our modeled value. Second, the length of model glaciers is sensitive to the complex elevation distribution of both area and slope. Because four glaciers with different geometries, elevations, and slopes are used, the calibration is highly sensitive to large changes in the two variables. Finally, our calibration values are reasonable for known climate characteristics of the area. The ELA, balance 


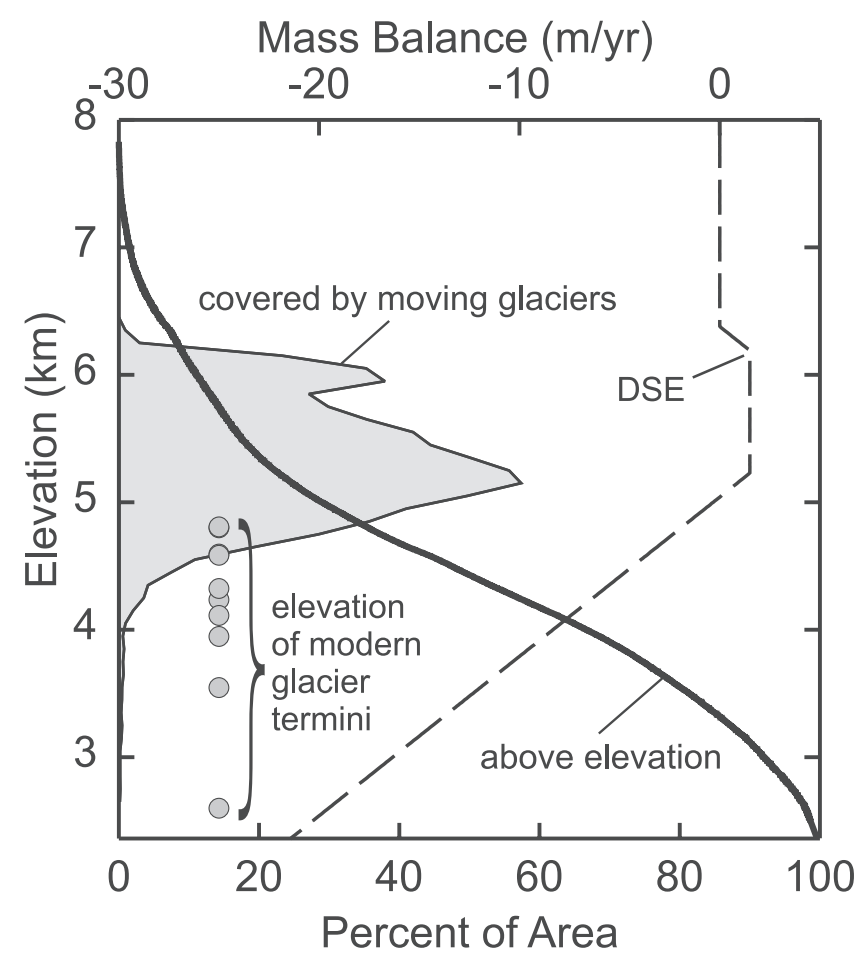

Figure 2. Hypsometry, glacial cover, and mass-balance of the region depicted in Figure 1. Thick curve = hypsometry, giving percent of total area (abscissa) above elevations (ordinate). Thin line $=$ percent of land area covered by positive ice flux (moving glaciers) under condition of diminishing snowfall at $6200 \mathrm{~m}$ (abscissa) verses elevation (ordinate). Circles $=$ elevations of the termini of 10 study glaciers (note: some points overlap). Dashed line = massbalance (units on upper abscissa) for best match between model and real-world glacier geometries. DSE = diminishing snowfall elevation.

gradient, and the maximum accumulation are close to measured values elsewhere in Nepal. Given our objective to investigate first-order processes, fractional adjustment of the calibration values do not have a significant impact on our results.

\subsection{Glacier Positions and Resolution}

[12] The terminus elevations of the 10 study glaciers were determined from satellite imagery and aerial photographs, map and digital elevation data, and were checked by ground observations. The lowest elevation along the active terminus front was selected. Termini of model glaciers were chosen in a similar manner. The position and elevation of model termini and real termini were discretized by the model grid and DEM, respectively. Because the model grid is hexagonal and the DEM grid is rectangular, there is an inherent error in inter comparisons. We consider discretization errors random, and estimate that they could be a maximum of $100 \mathrm{~m}$.

\section{Results and Discussion}

[13] The 10 study glaciers were investigated through 14 model runs with the DSE spanning elevations from $5550 \mathrm{~m}$ to above the entire landscape. Using model output we categorize the landscape into areas with ice (flux $\geq$ a $5-\mathrm{m}$ slab of ice moving at $1 \mathrm{~m} \mathrm{yr}-1$ ) and areas without ice flux (Figures 1 and 2). To evaluate DSE positioning, we compare each glacier's modeled terminus elevation against the terminus elevation of its real-world counterpart. For example, an overly high DSE causes the model glaciers to extend to lower elevation than the real-world glaciers (because of too much accumulation at high elevation) causing large negative differences between model and real terminus elevations.

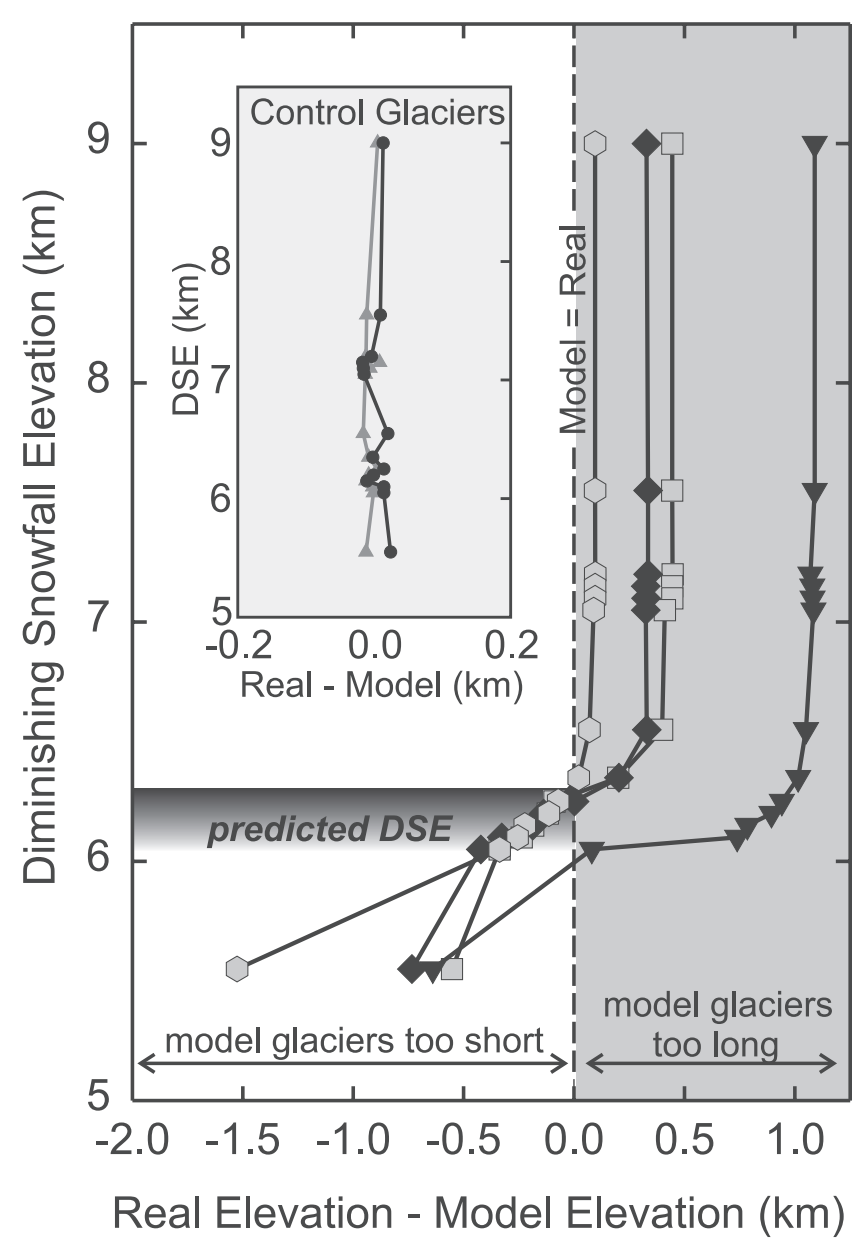

Figure 3. Difference between real-world and modeled terminus elevations. Data represent 14 model runs with different elevations of diminishing snowfall (DSE). For clarity, six of the ten study glaciers representing the range of results are shown in graph. Main panel shows four study glaciers: Glacier $10=$ triangles; Glacier $8=$ diamonds; Glacier 6 = squares; Glacier $9=$ hexagons. Ordinate is elevation of the DSE used in model runs. Abscissa is elevation difference between real-world termini and modeled termini: positive values indicate model termini extend to higher elevation than real-world termini; negative values indicated model termini lower than real-world termini. The best match between real-world and modeled termini is with the DSE at 6200-6300 m for all but Glacier 10, which has a better match at about $6000 \mathrm{~m}$. Inset shows two controlgroup glaciers (Glacier 2 = circles; Glacier $3=$ triangles) which demonstrate good agreement between model and realworld terminus elevations under mass-balance assumptions, regardless of DSE positioning. 
[14] The geometry of the four low-elevation glaciers remain unchanged as the DSE was varied, with differences between modeled and real terminus elevations of less than $\pm 10-20 \mathrm{~m}$ (Figure 3). This result is expected for proper calibration values with the slight variability between model runs due to discretization errors. The remaining six highelevation study glaciers were highly sensitive to the position of the DSE. When the DSE is so high that there is no diminished precipitation at high elevation, the modeled highelevation glaciers terminated 100 to $1000 \mathrm{~m}$ lower than the corresponding real-world glaciers (Figure 3). As the DSE was lowered, these glaciers shortened. The lower the DSE, the more sensitive the terminus positions were to the DSE due to increasing area with lower elevation (Figure 2). DSE values in the range of $6200-6300 \mathrm{~m}$ produced matching elevations between modeled termini and real-world termini for all but one glacier. Glacier 10 required a slightly lower DSE $(6000 \mathrm{~m})$ for a match, possibly because this is the only glacier at the head of a deep drainage. This glacier may consequently receive slightly more precipitation than the other glaciers.

[15] Our results do not imply that no snow whatsoever falls at high elevations; only that accumulating snowfall is limited and does not contribute significantly to glacial ice flux. The time scale relevant to our results must also be considered. Our results are based on constant climate parameters while the real-world glaciers exist under nonstationary climate. The study glaciers are all steep (therefore thin and fast flowing), and have strongly negative massbalances at their termini. Jóhannesson et al. [1989] show that terminus positions of glaciers with these characteristics respond relatively quickly to perturbations in mass-balance. From their analysis, we can expect the real-world terminus positions to represent climate averaged over decades, but not centuries. Our findings should therefore represent conditions averaged over decades.

\section{Conclusions}

[16] Glaciological modeling of the Annapurna Massif suggests the mass-balance curve depicted in Figure 2 is a good approximation of the study area's climate conditions. This implies 1) the ELA is about $5050 \mathrm{~m} \mathrm{2}$ ) the balance gradient and maximum accumulation are on the order of $8 \mathrm{~mm} / \mathrm{m}$ and $1 \mathrm{~m} / \mathrm{yr}$, respectively, and 3) above an elevation of 6200-6300 m precipitation diminishes rapidly with little snowfall on the high peaks. Our results show that no more than $60 \%$ of the area within the zone of modern glacierization is covered by actively moving ice. Further, a mass flux of ice is essentially non-existent over the upper $1000+\mathrm{m}$ of the terrain. Because glacial erosion scales with ice flux, we conclude there is no significant glacial erosion of the high summits. Models for erosion and uplift in the Himalaya must therefore consider the role of glacial erosion to be limited to an intermediate altitudinal band. Furthermore, during cold glacial episodes, this band should decrease in elevation, removing even more area at high elevation from coverage by actively moving ice.

[17] Acknowledgments. Funded by NSF Continental Dynamics Program (EAR 9909382). We thank Tank Ojha of Himalayan Experience for support of field logistics; Douglas Burbank and an anonymous referee for reviews of this manuscript.

\section{References}

Ageta, Y., and T. Kadota, Predictions of changes of glacier mass-balance in the Nepal Himalaya and Tibetan Plateau: A case study of air temperature increases for three glaciers, Annals Glaciol., 16, 89-94, 1992.

Bagchi, A. K., Orographic variation of precipitation in a high-rise Himalayan basin: Hydrological Aspects of Alpine and High Mountain Areas, IAHS, Publ. 138, 3-9, 1982.

Bahr, D. B., M. F. Meier, and S. D. Peckham, The physical basis of glacier volume-area modeling, J. Geophys. Res., 102(B9), 20,355-20,362, 1997.

Barros, A. P., M. Joshi, J. Putkonen, and D. W. Burbank, A study of the 1999 monsoon rainfall in a mountainous region in central Nepal using TRMM products and rain gauge observations, Geophys. Res. Lett., 27, $3683-3686,2000$.

Beaumont, C., P. Fullsack, and J. Hamilton, Erosional control of active compressional orogens, in Thrust Tectonics, edited by K. R. McClay, 1-18, Chapman and Hall, New York, 1992.

Blatter, H., Velocity and stress fields in grounded glaciers: A simple algorithm for including deviatoric stress gradients, J. Glaciol., 41, 333-344, 1995

Burbank, D. W., J. Leland, E. Fielding, R. S. Anderson, N. Brozovic, M. R. Reid, and C. Duncan, Bedrock incision, rock uplift and threshold hillslopes in the northwestern Himalayas, Nature, 379, 505-510, 1996.

Carruthers, D. J., and T. W. Choularton, The microstructure of hill cap clouds, Q. J. R. Meteorol. Soc., 112, 113-129, 1986.

Choularton, T. W., and S. J. Perry, A model of the orographic enhancement of snowfall by the seeder-feeder mechanism, Q. J. R. Meteorol. Soc., 112, $335-345,1986$

Dyurgerov, M., Glacier mass-balance and regime: Data of measurements and analysis, INSTAAR, Occasional paper 55, Boulder, Univ. of Colorado, 2002.

Fujita, K., T. Kadota, B. Rana, R. B. Kayastha, and Y. Ageta, Shrinkage of Glacier AX010 in Shorong region, Nepal Himalayas in the 1990s, Bull. Glaciol. Res., 18, 51-54, 2001.

Harper, J. T., N. F. Humphrey, W. T. Pfeffer, S. V. Huzurbazar, D. B. Bahr, and B. C. Welch, Spatial variability in the flow of a valley glacier: Deformation of a large array of boreholes, J. Geophy. Res., 106(B5), 8547-8562, 2001.

Higuchi, K. Y., Y. Ageta, T. Yasunari, and J. Inoue, Characteristics of precipitation during the monsoon season in high-mountain areas of the Nepal Himalaya: Hydrological Aspects of Alpine and High Mountain Areas, IAHS, Publ. 138, 21-30, 1982.

Hostetler, S. W., and P. U. Clark, Tropical climate at the last glacial maximum inferred from glacier mass-balance modeling, Science, 290, 17471750,2000

Jóhannesson, T., C. Raymond, and E. Waddington, Time scale for adjustment of glaciers to changes in mass-balance, J. Glaciol., 35, 355-369, 1989.

Kuhle, M., The upper limit of glaciation in the Himalayas, Geo J., 13.4, $331-346,1986$.

Nye, J. F., The flow of glaciers and ice-sheets as a problem in plasticity, Proc. Royal Soc., Ser. A., 229, 554-572, 1951.

Paterson, W. S. B., The Physics of glaciers, Elsevier, Tarrytown, New York, 1994.

Shrestha, M. L., Interannual variation of summer monsoon rainfall over Nepal and its relation to Southern Oscillation Index, Meterol. Atmos. Phys., 75, 21-28, 2000.

Willett, S. D., Orogeny and orography: The effects of erosion on the structure of mountain belts, J. Geophys. Res., 104, 28,957-28,981, 1999.

J. T. Harper and N. F. Humphrey, Department of Geology and Geophysics, University of Wyoming, Laramie, WY 82071, USA. (joelh@) uwyo.edu; neil@uwyo.edu) 